\title{
AVALIAÇÃO DOS FATORES RELACIONADOS À NÃO ADESÃO À SEGUNDA DOSE DA VACINA H1N1 EM UM CENTRO DE SAÚDE-ESCOLA
}

\author{
EVALUATION OF FACTORS RELATED TO THE NON-ADHERENCE \\ TO A SECOND DOSE OF H1N1 VACCINE
}

\author{
Lucas de Paiva Dias ${ }^{a}$, Marcos de Paiva Dias ${ }^{b}$ \\ alucaspaivaenf@gmail.com, bmarcosdepaivadias@hotmail.com \\ Universidade Federal de Uberlândia - Uberlândia (MG), Brasil
}

Data de recebimento do artigo: 15/02/2017

Data de aceite do artigo: 13/03/2017

\section{RESUMO}

Introdução: Vacinar crianças a partir dos primeiros meses de idade é uma ação de proteção específica contra doenças graves, incluindo a H1N1, responsável por elevadas taxas de morbimortalidade infantil. Objetivo: $\mathrm{O}$ propósito desta pesquisa foi analisar os fatores que levam as máes/acompanhantes de crianças de 0 a 2 anos a não manterem o cartão de vacina das crianças em dia na sala de vacinaçấo, mostrar as influências dos aspectos sociais e epidemiológicos, evidenciar as questóes culturais e caracterizar o perfil dos pais em relação à vacina H1N1. Materiais e métodos: Trata-se de um estudo descritivo-exploratório sobre os fatores da não adesão à $2^{\text {a }}$ dose da vacina contra a $\mathrm{H} 1 \mathrm{~N} 1 \mathrm{em}$ um centro de saúde-escola. Para tanto, foi realizada uma pesquisa de campo, utilizando um formulário com 8 perguntas fechadas e 1 pergunta aberta. A coleta de dados aconteceu em local agendado pelo sujeito da pesquisa, após aprovação pelo Comitê de Ética em Pesquisa com Seres Humanos (CEP). Resultados: Entre os participantes, a mulher é a personagem principal no trato de questóes de saúde, correspondendo a $85 \%$ dos entrevistados. Ficou claro que $54 \%$ gastaram até 10 minutos para chegar à unidade de saúde. Observou-se que $46 \%$ da população pesquisada não terminou o segundo grau. Conclusóes: Os dados socioepidemiológicos e culturais não influenciaram a não adesão à $2^{\mathrm{a}}$ dose da vacina contra H1N1. Após a análise das entrevistas, foi possível observar que existem fatores como: ausência de informação quanto à necessidade do retorno à unidade de saúde para completar o esquema de vacinação; descompasso entre a informação da ficha de registro na unidade de saúde e o que estava anotado no cartão da criança; e falta de vacina na unidade, o que interfere a atualização do cartão das crianças. Portanto, ressalta-se a importância da busca ativa dos faltosos para se obter dados fidedignos quanto à cobertura vacinal. Essa temática poderá ser mais explorada em pesquisas futuras, pois há muitas questôes complexas relacionadas à não adesão à vacina H1N1.

Palavras-chave: Criança; H1N1; influenza; vacina; adesão.

\section{ABSTRACT}

Introduction: Vaccinating babies is an action for specific protection against serious diseases, including H1N1, responsible for high rates of morbidity and mortality. Objective: The purpose of this research was to analyze the factors that made mothers/caregivers not update the card vaccine of babies aged 0-2 years and show the influences of cultural, social and epidemiological aspects to characterize the profile of parents regarding the $\mathrm{H} 1 \mathrm{~N} 1$ vaccine. Materials and methods: This is a descriptive exploratory study on the factors of the non-adherence to the $2^{\text {nd }}$ dose of $\mathrm{H} 1 \mathrm{~N} 1$ vaccine in a school health center. The participants answered a questionnaire containing 8 objective tests and 1 essay question. Data collection was made in place scheduled by a researcher, after approval by the Research Ethics Committee (CEP). Results: Participants included woman as the main responsible for dealing with health issues, corresponding to $85 \%$ of the interviewed. It was clear that $54 \%$ spent up to 10 minutes to reach the health facility. It was 
observed that $46 \%$ of the population surveyed did not finish high school. Conclusions: Socioepidemiological and cultural data did not influence the non-adherence to the $2^{\text {nd }}$ dose of $\mathrm{H} 1 \mathrm{~N} 1$ vaccine. After analyzing the interviews, the main factors that affected the treatment were: lack of information about the need to return to the clinic to complete the vaccination course, the gap between the information given at the health unit and what was noted in the child's card, and the lack of vaccines in health centers. Therefore, we emphasize the importance of active search for missing cases to obtain reliable data regarding vaccine coverage. This theme should be further explored in future research, as there are many complex issues related to the non-adherence to $\mathrm{H} 1 \mathrm{~N} 1$ vaccine.

Abstract: Child; H1N1; influenza; vaccination; adherence.

\section{Introdução}

A influenza (ou gripe) é uma infecção viral que afeta o sistema respiratório, mais precisamente o nariz, a garganta e os brônquios. O contágio de forma direta ocorre através das secreções das vias respiratórias da pessoa contaminada ao falar, tossir ou espirrar; e de forma indireta por meio das mãos, que após contato com superfícies recém-contaminadas por secreçóes respiratórias, podem levar o agente infeccioso direto à boca, aos olhos e ao nariz ${ }^{1}$. É de elevada transmissibilidade e distribuição global, com tendência a se disseminar facilmente em epidemias sazonais ${ }^{2}$.

Os vírus influenza são da família dos Ortomixovirus e subdividem-se em três tipos: $\mathrm{A}, \mathrm{B}$ e $\mathrm{C}$, de acordo com sua diversidade antigênica, podendo sofrer mutaçóes. $\mathrm{O}$ vírus A é o mais mutável entre eles, sendo o maior responsável pelas pandemias desse tipo viral ${ }^{2}$.

A maioria das pessoas infectadas se recupera dentro de uma a duas semanas sem necessidade de tratamento médico. No entanto, nas crianças muito pequenas, idosos, portadores de quadros clínicos especiais, gestantes e pessoas com histórico de patologias crônicas, a infecção pode chegar a formas clinicamente graves, como pneumonia e síndrome respiratória aguda grave (SRAG), que podem levar o acometido a óbito ${ }^{2}$. O controle da influenza requer uma vigilância qualificada, somada às açōes de imunizaçōes anuais, direcionadas especificamente aos grupos de maior vulnerabilidade, que incluem os idosos, crianças, povos indígenas, trabalhadores de saúde, gestantes e, agora, população presidiária ${ }^{2}$.

Em março de 2009, iniciou-se uma epidemia de gripe no México, causada por uma nova variante do vírus influenza $\mathrm{A}(\mathrm{H} 1 \mathrm{~N} 1)^{3}$, originada de um vírus que circula entre os porcos desde o fim da década de 1990. Em pouco tempo, casos semelhantes ocorreram em outros países, alertando as autoridades sanitárias para o risco de uma pandemia (de dezembro de 2005 a fevereiro de 2009, tem-se notícia de dezesseis casos desse vírus, que foi popularmente chamado de "gripe suína") ${ }^{4}$.

Ao longo da história, constatou-se a ocorrência de várias pandemias de gripe. $\mathrm{O}$ primeiro relato de gripe suína foi feito por Hipócrates em 412 a.C., o qual alega que uma doença respiratória matou muitas pessoas em poucas semanas e depois desapareceu ${ }^{5}$. No século XX, registraram-se a gripe espanhola (1918), a asiática (1957 a 1963) e a de Hong Kong (1968 a 1970): a primeira é considerada a pior pandemia de todos os tempos, dizimando de 40 a 100 milhóes de pessoas em todo o mundo; a segunda vitimou cerca de 2 milhóes; e a terceira, em torno de 1 milháo de pessoas ${ }^{6}$.

Essas pandemias tiveram como características a alta mortalidade entre os jovens; a evolução em ondas epidêmicas, sendo a primeira mais branda e as demais com uma severidade maior; índices de transmissão mais elevados do que as gripes sazonais, além da heterogeneidade regional, justificada pela complexidade das características imunológicas dos habitantes, os subtipos de vírus circulantes e os detalhes geográficos e climáticos das áreas afetadas ${ }^{6}$.

$\mathrm{Na}$ primeira quinzena de abril de 2009, os sistemas de vigilância epidemiológica do México e da Califórnia (EUA) passaram a receber notificaçáo de casos de infecção humana com vírus da influenza $\mathrm{A}$, ainda não definidos quanto ao subtipo antigênico; na segunda quinzena, a Organização Mundial de Saúde (OMS) divulgou alerta sobre a nova epidemia, e aproximadamente três semanas depois já haviam sido notificados quase 10 mil casos de influenza A H1N1, com 79 mortes confirmadas 7.

No Brasil, em 25 de abril de 2009, a epidemia foi declarada emergência de saúde pública de importância internacional (ESPII), e até o dia 6 de julho o total de episódios confirmados pelo Ministério da Saúde (MS) chegou a 905, com notificaçóes de 23 estados e do Distrito Federal. Os estados com maior número de casos foram: São Paulo (402), Rio Grande do Sul (111), Rio de Janeiro (91), Minas Gerais (90), Santa Catarina (56), Paraná (36), Distrito Federal (31), Espírito Santo (11), Bahia (8), Mato Grosso (4), a maioria com evolução benigna, e houve uma morte no Rio Grande do Sul ${ }^{7}$.

Como parte do processo de enfrentamento da epidemia em Minas Gerais, foi estabelecido, em 26 de junho daquele ano, no Hospital das Clínicas da Universidade Federal de Minas Gerais (UFMG), o primeiro ambulatório especializado em atendimento a pacientes com suspeita de terem contraído a influenza A H1N1 em 
Belo Horizonte e, em seguida, no Hospital Eduardo de Menezes (Fundação Hospitalar do Estado de Minas Gerais - Fhemig) e no Hospital Felício Rocho7.

As manifestaçóes clínicas da infecção pelo vírus influenza A (H1N1) são semelhantes às da gripe comum, com febre, tosse, mialgia, fadiga, cefaleia, rinorreia, vômitos e diarreia. Os grupos de risco incluem crianças menores de 2 anos e idosos acima de 60 anos, gestantes, portadores de imunossupressão e indivíduos com comorbidades crônicas ${ }^{8}$.

O MS adotou a Estratégia Nacional de Vacinação Contra o Vírus da Influenza Pandêmica (H1N1) 2009, que se fundamentou - conjuntamente - na análise de vários fatores, entre eles a situaçấo epidemiológica no Brasil, a vigência da segunda onda da pandemia no hemisfério Norte, a gravidade da doença, o risco de adoecer e morrer e a disponibilidade da vacina. A estratégia nacional de vacinação foi realizada em cinco etapas, com definição de grupos prioritários. Inclui-se, na $2^{\text {a }}$ etapa, a vacinação de crianças, pois as taxas de hospitalização, na vigência da pandemia, foram elevadas em crianças muito pequenas, com percentual de até $10 \%$. Das que necessitaram de internação, $10 \%$ a $15 \%$ demandaram atençâoo diferenciada em unidades de cuidados intensivos e, destas, $2 \%$ a $9 \%$ foram a óbito 9 .

O governo brasileiro, com base nas experiências de outras campanhas de imunização, estreitou ainda mais a parceria com várias instituiçóes e entidades, para estabelecer a estratégia de enfrentamento da influenza pandêmica (H1N1) 20099. Vacinar crianças a partir dos primeiros meses de idade é uma ação de proteçáo específica contra doenças graves, causadoras de danos definitivos ou letais, e, assim, metas de vacinação foram estabelecidas, com o objetivo de alcançar níveis adequados de imunidade coletiva, capazes de impedir a transmissão das doenças imunopreveníveis ${ }^{10}$.

O Brasil tem feito pesquisas para identificar, conhecer e fornecer informaçôes sobre os determinantes e condicionantes de saúde, as desigualdades, necessidades e o uso dos serviços de saúde na população. Esses estudos têm como objetivo orientar o desenvolvimento de açôes de prevenção, avaliar o impacto das intervenções, subsidiar a formulação de políticas públicas e apoiar o planejamento em saúde e áreas afins?

Dessa forma, este trabalho se justifica na importância de conhecer as características sociais, epidemiológicas e demográficas de famílias que não levaram seus filhos para a administração da $2^{a}$ dose da vacina contra H1N1 e os principais fatores da não adesão. Verificar a adesão à vacina é importante, pois quando se observa que crianças estão com vacinas atrasadas, é necessário fazer a busca ativa.

Objetiva-se analisar os fatores que levam os pais/familiares de crianças de 0 a 2 anos a não manterem o cartão da 2a dose da vacinação contra a H1N1 em dia no Centro de Saúde-Escola Jaraguá (CSE) da Universidade Federal de Uberlândia (UFU) e caracterizar seus perfis social, epidemiológico e demográfico.

\section{Métodos e metodologia}

Trata-se de um estudo descritivo-exploratório de campo, com abordagem quantitativa sobre os fatores da não adesão, e o projeto foi executado com os pais/familiares de crianças assistidas do referido centro. De acordo com os dados obtidos, o local iniciou suas atividades em 1983, em convênio com a prefeitura de Uberlândia. $\mathrm{Na}$ época, a Secretaria de Açáo Social era uma das cinco unidades didáticas avançadas (UDAs) do complexo assistencial da UFU.

Atualmente, o CSE Jaraguá, além de abrigar atividades didáticas, é uma das unidades básicas de saúde (UBS) que compóem o Distrito Oeste de Uberlândia, trabalha dentro do plano diretor e sendo responsável pela assistência à população de sua área (bairros Jaraguá, Tubalina e Valle, com uma população estimada de 250 mil pessoas. Ou seja, o local é a "porta de entrada" ao Sistema Único de Saúde (SUS) para os moradores do entorno, excluindo-se as situaçōes de emergência, nas quais os pacientes seriam acolhidos por um serviço de atendimento, para então acessarem os serviços necessários em outros níveis da rede, como a Unidade de Acolhimento Infantil (UAI).

Os serviços oferecidos pelo CSE Jaraguá são: acolhimento; imunização; serviço social; psicologia; saúde da criança; adolescente e adultos; saúde do adulto; saúde da mulher; especialista; e atendimento de enfermagem.

As açôes programáticas desenvolvidas são: controle de hanseníase; tuberculose; diabetes; hipertensão arterial; pré-natal; vigilância ao recém-nascido; puericultura; atendimento às creches; saúde escolar; prevenção de câncer de colo uterino; prevenção de câncer de mama; climatério; planejamento familiar e saúde mental. De acordo com os dados fornecidos pela coordenação do local, 264 crianças foram assistidas no período de 2008 a 2009.

Em 2015, de um total de 165 crianças cadastradas na sala de vacina da unidade de saúde, 80 completaram a $2^{a}$ dose, e 27 não retornaram para recebê-la. Em 2016, do total de 99 crianças, 62 completaram a $2^{\text {a }}$ dose; e 14 , apenas a $1^{\text {a }}$.

Mediante dados oferecidos pelo local e critérios de inclusão/exclusão definidos no projeto, foram entrevistados 14 pais/familiares. Foram escolhidas as fichas de aprazamento de todas as crianças situadas na faixa etária de 0 a 2 anos vacinadas com a $1^{\text {a }}$ dose da vacina HIN1. Foram incluídos os pais/familiares que não levaram seus filhos para receberem a $2^{a}$ dose da vacina e que possuíssem 
endereço e telefone completos na ficha. Os pesquisadores formularam 8 perguntas fechadas e 1 questão aberta, tendo como referencial teórico o trabalho de $\mathrm{Gil}^{11}$. Os formulários foram aplicados aos sujeitos da pesquisa após as devidas orientaçôes para preenchê-los.

O projeto foi encaminhado ao Comitê de Ética em Pesquisa (CEP) da UFU. Mediante a aprovação pelo CEP, iniciou-se a coleta dos dados por meio de entrevistas (Anexo) realizadas em local agendado. Os participantes foram abordados pelo pesquisador, do qual receberam os esclarecimentos acerca do caráter e dos objetivos da pesquisa, e foram então convidados a participar. Eles assinaram o Termo de Consentimento Livre e Esclarecido antes de responder o questionário. O período de coleta de dados ocorreu de janeiro a dezembro de 2015, segundo a disponibilidade e de acordo com os critérios de inclusão e exclusão. Os resultados observados nos formulários foram agrupados e analisados conforme o método escolhido para desenvolver o projeto.

As dificuldades encontradas estavam relacionadas com a não localização dos sujeitos de pesquisa para agendar as entrevistas, mesmo após uma média de cinco tentativas de contato, pois ou os telefones não existiam mais ou os participantes estavam com endereços desatualizados, além da falta de tempo e de disponibilidade de alguns.

O projeto foi realizado de acordo com a Resolução 196/96 do Conselho Nacional de Saúde, e os entrevistados tiveram sua identidade preservada. Aqueles que se recusaram a participar da pesquisa tiveram sua decisão respeitada.

\section{Resultados}

"Imunização" significa a indução de forma natural ou artificial da resposta imune, em particular quando dá ao hospedeiro a capacidade de proteção contra a doença; "vacinação" significa a imunização com antígenos administrados para prevenir doenças infecciosas. Portanto, a vacinação é uma imunização artificial, e a prevenção visa o emprego de medidas profiláticas, a fim de impedir que indivíduos sadios adoeçam. Assim, leva-se a refletir o quanto um esquema vacinal completo e atualizado é importante para a promoção da saúde ${ }^{12}$.

A história recente da política de imunizaçóes no país tem como marco o ano de 1973, com o término da campanha de erradicação da varíola, iniciada em 1962, e a criação do Programa Nacional de Imunizaçóes (PNI) ${ }^{12}$ a partir de uma proposta básica elaborada por técnicos do Departamento Nacional de Profilaxia e Controle de Doenças (MS e Central de Medicamentos - CEME) e renomados sanitaristas e infectologistas ${ }^{13}$, que visa controlar ou erradicar doenças infectocontagiosas e imunopreviníveis, tais como a poliomielite (paralisia infantil), sarampo, difteria, tétano, coqueluche, tuberculose e outras, mediante a imunização sistemática da populaçãa ${ }^{13}$.

O PNI é parte integrante do programa da OMS, com o apoio técnico, operacional e financeiro do Fundo das Nações Unidas para a Infância (Unicef) e contribuições do Rotary International e do Programa das Naçóes Unidas para o Desenvolvimento (PNUD) ${ }^{9}$. Sua gestão nacional compete à Coordenação de Imunizações e Autossuficiência em Imunobiológicos (CIAM) do Centro Nacional de Epidemiologia (Cenep1) da Fundaçáo Nacional de Saúde (Funasa) ${ }^{13}$; sua informatização do foi desenvolvida pelo Departamento de Informática do SUS e pela Gerência Técnica de Sistemas Ambulatoriais (GTSA), sendo especificação da CIAM $^{13}$; sua criação deu-se no âmbito da formulação de grandes programas nacionais, na gestão do ministro Mário Machado de Lemos ${ }^{14}$.

Seu documento conceitual refere como exigências programáticas estender as vacinaçóes às áreas rurais, aperfeiçoar a vigilância epidemiológica em todo o território nacional, capacitar laboratórios oficiais para a respaldarem com diagnóstico, instituir pelo menos um laboratório nacional de referência para controlar a qualidade das vacinas, racionalizar sua aquisição e distribuição e uniformizar as técnicas de administração, além de promover a educação em saúde para aumentar a receptividade da população aos programas de vacinação ${ }^{14}$.

A vacinação contra a influenza pandêmica $H 1 N 1$ num mesmo ano demonstram a alta capacidade técnica do PNI e do MS, inclusive nas questóes de logística para imunização ${ }^{15}$. Em 11 de junho de 2009, a OMS elevou a epidemia de influenza $\mathrm{A}(\mathrm{H} 1 \mathrm{~N} 1)$ para o nível máximo de alerta (nível 6), oficialmente declarando que o mundo estava em pandemia pela nova gripe, considerada "incontrolável" "15,16

A pandemia de H1N1 chegou ao estado do Paraná no início de junho de 2009. Em pouco tempo, tornou-se um dos estados com maior incidência e mortalidade da doença no Brasil, aparentemente por estar na fronteira com a Argentina, país que, com o Chile, teve os primeiros casos de H1N1 na América do Sul ${ }^{17}$.

Para que ocorra uma pandemia, são necessários três pré-requisitos: 1) o aparecimento de um novo vírus para o qual a populaçáo humana tenha baixa ou nenhuma imunidade; 2) o vírus ter a capacidade de se replicar em humanos e causar doença grave; e 3) o vírus deve ser transmitido facilmente entre humanos ${ }^{17}$.

A OMS desenvolveu um protocolo de operaçóes em caso de deflagração da pandemia e recomenda que todos os países desenvolvam seus planos de controle 5 . Em 2009, a OMS vivenciou sua função fundamental de coordenadora global das questôes de vacinação, no 
desenvolvimento e produção rápida da vacina contra H1N1. Graças à forte coordenação, congregando as instituiçóes públicas, privadas e peritos da área, foi possível, num prazo relativamente curto de sete meses desde a primeira notificação da doença no México até a primeira vacina, registrada em novembro de 2009 -, desenvolver uma vacina contra o vírus $\mathrm{H} 1 \mathrm{~N} 1^{16}$.

Até 13 de agosto de 2009, foram registrados no mundo 182.166 casos confirmados de influenza A/H1N1 e 1.799 óbitos, tendo o maior contingente sido registrado na região das américas ${ }^{18}$. Desde 16 de julho de 2009, após a declaração de transmissão sustentada, o MS, em articulação com as secretarias de saúde dos estados e municípios, realiza a vigilância epidemiológica de síndrome respiratória aguda grave (SRAG). Entre os casos de síndrome gripal, são priorizadas a notificação, a investigação, o diagnóstico laboratorial e o tratamento dos casos com SRAG - estratégia orientada pela OMS que tem sido adotada pelos países com transmissão sustentada, uma vez que qualquer pessoa que apresente síndrome gripal é um caso potencial de influenza $\mathrm{A} / \mathrm{H} 1 \mathrm{~N} 1^{18}$.

As vacinas contra o vírus são alteradas anualmente, com base nas recomendaçóes da OMS. Para tal, desde 1947, centros de vigilância epidemiológica da gripe são coordenados em várias partes do mundo, envolvendo atualmente cerca de 110 laboratórios em 80 países, os quais sistematicamente coletam amostras de secreçóes respiratórias dos pacientes com quadro clínico de gripe ${ }^{19}$.

Ao final do mês de fevereiro de cada ano, um grupo de especialistas da OMS se reúne para avaliar os dados epidemiológicos coletados no ano anterior e recomendar as cepas de vírus influenza que terão maior chance de causar epidemias no ano subsequente - estas deverão compor a vacina a ser utilizada no inverno daquele ano em países do hemisfério Norte. O mesmo procedimento é realizado no final de setembro em Melbourne, na Austrália, para definir a composição da vacina para o hemisfério Sul ${ }^{19}$. A vacinação contra a influenza tem sido a medida de maior efetividade no enfrentamento do problema, indicada pela OMS desde $1963^{20}$.

\section{Discussão}

Trata-se de um estudo descritivo-exploratório sobre os fatores da não adesão à vacinação da influenza pandêmica no CSE Jaraguá. A amostra obtida para o desenvolvimento da pesquisa, de acordo com os critérios de inclusão e exclusão, contou com a participação de 14 pais/familiares. Sendo escolhidas as fichas de aprazamento de todas as crianças situadas na faixa etárias de 0 a 2 anos vacinadas com a $1^{\text {a }}$ dose da vacina contra H1N1.

Os dados desta pesquisa foram tabulados, organizados e apresentados em gráficos utilizando a estatística descritiva simples. A seguir, procedeu-se à análise, com embasamento no referencial teórico citado na pesquisa, além do uso de dados atualizados do MS (Gráfico 1).

Gráfico 1: Grau de parentesco dos responsáveis por levar as crianças para serem vacinadas.

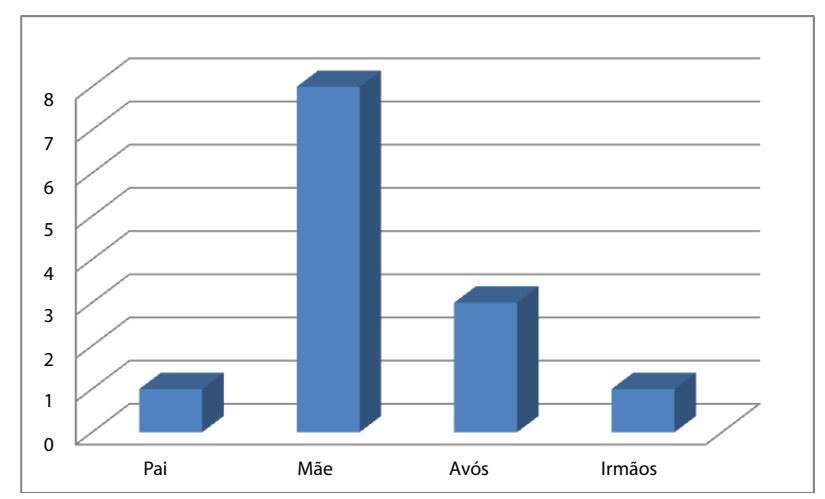

Para iniciar a análise, foi verificado o grau de parentesco dos responsáveis por levar as crianças para serem vacinadas ao local supracitado. Segundo Castilho e Bercini ${ }^{21}$, a administração da saúde e da higiene da família é feita pela mulher/mãe de família, cabendo a ela a tomada de decisão quanto ao que fazer e o encaminhamento a dar à criança, assim como as práticas e as concepções que circulam no lar nesse terreno, sendo também as depositárias das tradiçôes a esse respeito.

De forma geral, entre os entrevistados, a mulher é a personagem principal no trato de questôes de saúde e doença, sendo ela quem cuida da criança e toma a decisão de procurar o serviço de saúde quando necessário, além de ter um contato mais frequente com os profissionais de saúde.

Gutierrez e Minayo ${ }^{22}$ apontam que, nos cuidados da saúde no âmbito da família, a figura da mulher-mãe como principal cuidadora é um consenso e que há vários estudos que ressaltam o cuidado pela mulher enquanto um fenômeno mundial. Esposas e filhas são as cuidadoras mais frequentes; noras e irmãs aparecem com menor frequência. Isso significa que cuidado é quase sinônimo de mulher. Os trabalhos pouco exploram os cuidados oferecidos por outros membros. Mães e avós cuidam de crianças e de outras mulheres, enquanto as esposas e filhas cuidam dos idosos.

As dificuldades de integração da vida profissional com a vida doméstica têm causado um crescimento das desigualdades entre segmentos de mulheres. A responsabilidade pelos cuidados com crianças ou idosos atinge fundamentalmente as mulheres, e é nesse ponto que as políticas públicas têm um papel fundamental.

A faixa etária dos responsáveis por levar as crianças para serem vacinadas também foi investigada (Gráfico 2). 
Gráfico 2: Faixa etária dos responsáveis por levar as crianças para serem vacinadas.

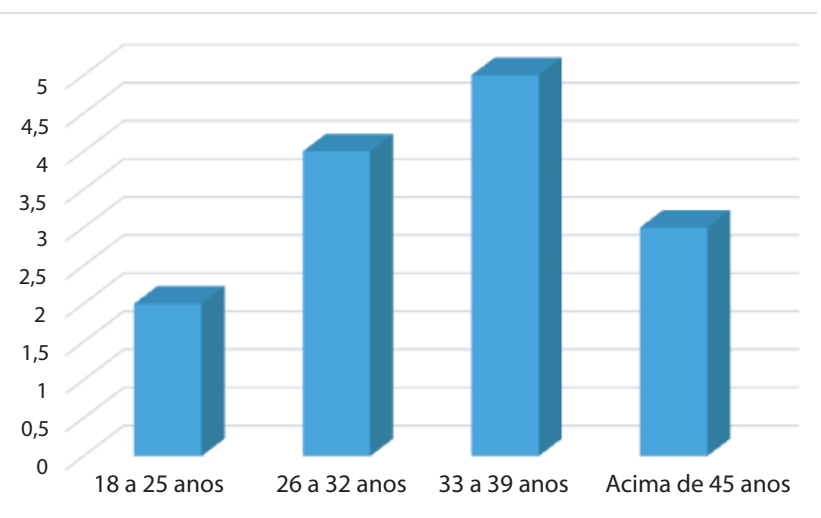

Como mostra o Gráfico 2, as faixas etárias situaram-se com maior abrangência entre 26 a 32 anos e 33 a 39 anos, correspondendo a $64,29 \%$; as avós representam $22 \%$ dos responsáveis.

Estudos como o de Rocha et al. ${ }^{23}$ evidenciam que a faixa etária das mães, em especial as adolescentes, é um elemento que potencializa a não adesão ao esquema vacinal do PNI. No entanto, no presente estudo não foi possível correlacionar esses dados considerando o número de sujeitos participantes.

Visando conhecer as facilidades e dificuldades encontradas na tarefa de levar as crianças, buscou-se conhecer o tempo gasto e os meios de locomoção da residência à unidade de saúde pelos responsáveis das crianças, conforme os Gráficos 3 e 4.

Gráfico 3: Tempo gasto da residência à unidade de saúde pelos responsáveis das crianças a serem vacinadas.

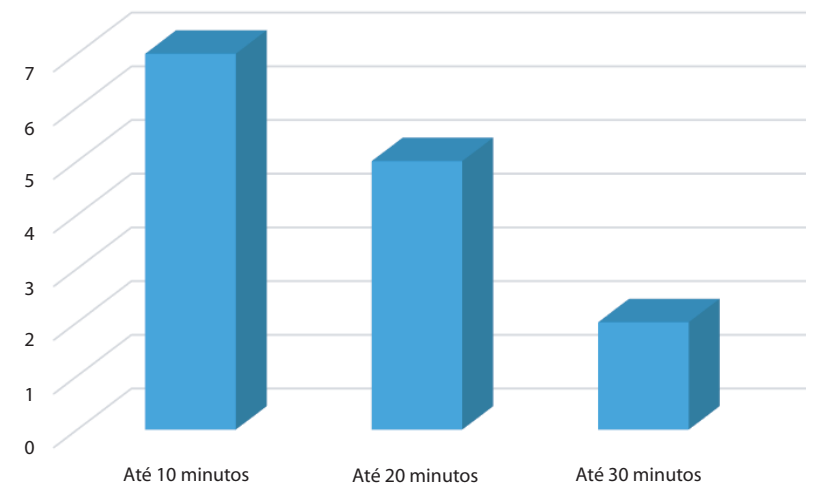

Como mostram Moscon e Krüger ${ }^{24}$, o acesso da população aos serviços de saúde é um tema que vem tomando corpo, tendo em vista que a universalidade do acesso é o primeiro dos treze princípios do SUS. Uma série de fatores condicionam e envolvem a disponibilidade de serviços e de transporte, inclusive distâncias geográficas. $\mathrm{O}$ acesso envolve um conjunto de elementos culturais, políticos e econômicos em relação aos serviços de saúde que historicamente vêm sendo ofertados a uma população.

Observa-se que o tempo gasto pelos responsáveis das crianças para levá-los está diretamente relacionado ao meio de locomoção utilizado para chegar à unidade de saúde: $50 \%$ dos entrevistados gastaram até 10 minutos para chegar à unidade de saúde utilizando carro.

Os indivíduos que gastaram até 20 minutos utilizaram ônibus ou foram a pé. Já os que gastaram até 30 minutos foram a pé. Esses dados corroboram o estudo de Figueiredo et al..$^{25}$, que mostra a associação entre residência mais próxima e cobertura vacinal, apontando como causas as dificuldades ou falta de acesso ao serviço de saúde e ao transporte, ou seja, quanto mais próximo, mais fácil o acesso à unidade de saúde.

Como apresenta o Instituto Brasileiro de Geografia e Estatística (IBGE) ${ }^{26}$ na síntese dos indicadores sociais, o aumento da participação na categoria empregada com carteira de trabalho assinada, entre as mulheres, passa de 24,2\%, em 1999, para 30,3\%, em 2009. A falta de tempo em decorrência do aumento de trabalho atrapalha as mulheres a levar as crianças ao centro de saúde mais próximo de casa.

Também foi possível conhecer o grupo étnico representado pela amostra da pesquisa. Verifica-se que a amostra é representada igualmente por brancos e negros (46\%), e o restante, por pardos (8\%) (Gráfico 5).

De acordo com o Censo Demográfico 201027, os dados relacionados à etnia mostram que o Brasil conta com uma população de 191 milhôes de habitantes, dos quais $47,7 \%$ se classificaram como brancos; $7,6 \%$ como negros e $43,1 \%$ como pardos. Se comparados com os dados da pesquisa. Apesar da diferença dos dados entre a presente pesquisa e o IBGE, não foi possível ampliar essa análise, considerando não ser o foco desta investigação.

Como afirma Adorno, Alvarenga e Vasconcellos ${ }^{28}$, a temática raça/etnia esteve ausente dos textos oficiais e do debate no campo da saúde pública no Brasil. Nas últimas décadas, veio recentemente se constituir em um dos "novos" problemas para investigação e debate. Pode-se considerar a relevância de tomar essa questão como problema de investigação no campo da saúde pública, pois apresenta sua complexidade e natureza pluri e interdisciplinar, dadas as próprias características fundamentais desse campo de conhecimento e de prática.

Os aspectos culturais influenciam na tomada de decisão para que os responsáveis levem os filhos para serem vacinados. Estudos como de Rocha et al. ${ }^{23}$ mostram que a etnia influencia a completa adesão ao esquema de vacinação de programas de imunização. Por isso houve a preocupação em citar os dados sobre a etnia. 
Gráfico 4: Meios de locomoção utilizados pelos responsáveis por levar as crianças a serem vacinadas.

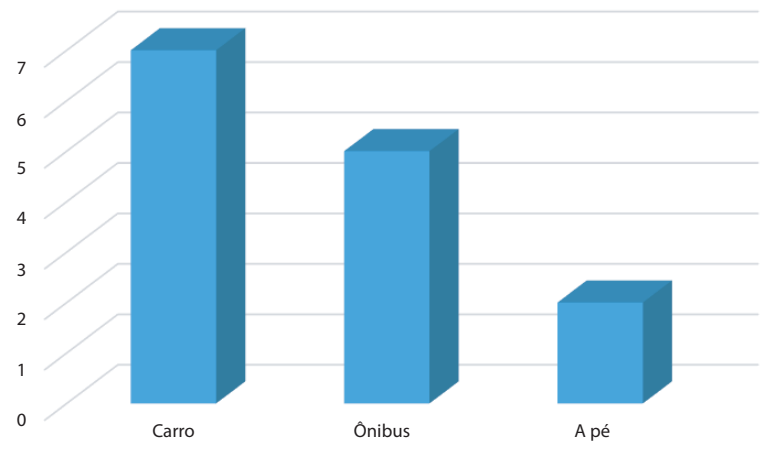

Gráfico 5: Etnia dos responsáveis por levar as crianças para serem vacinadas.

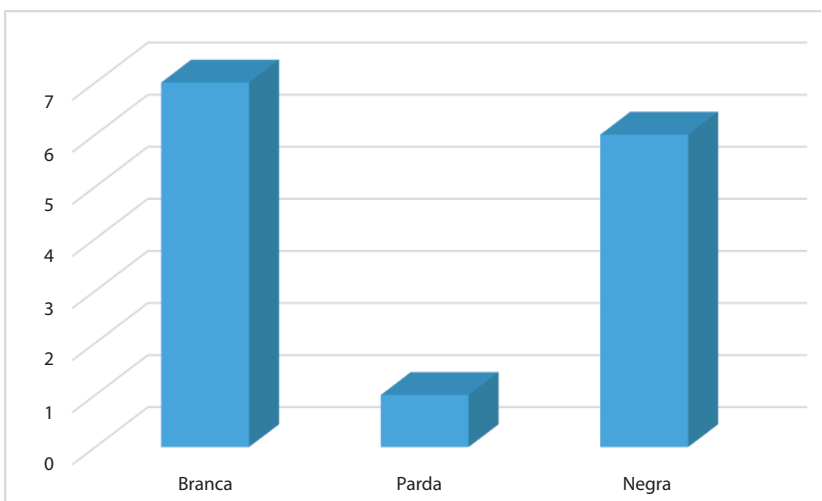

Quanto à religião, a maioria da população pesquisada informou pertencer à religião católica $(57,14 \%)$; $(21,43 \%)$ informaram ser evangélicos; $(14,29 \%)$ espíritas e outros $(7,14 \%)$ (Gráfico 6).

Gráfico 6: Religião dos responsáveis por levar as crianças para serem vacinadas.

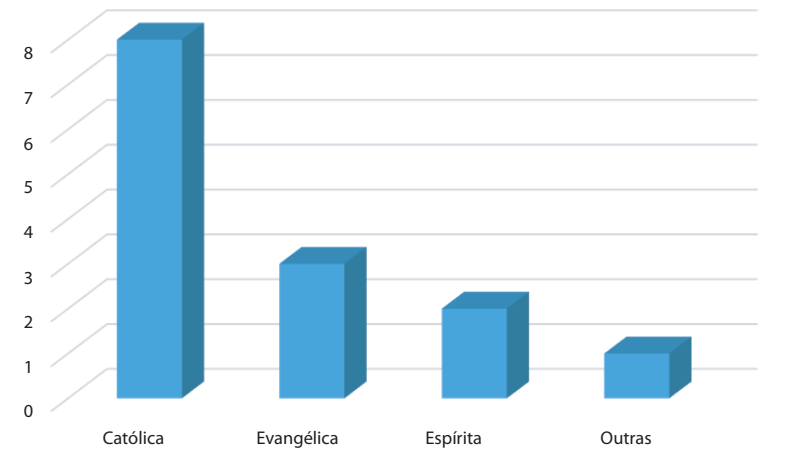

Segundo Raymundi ${ }^{29}$, a influência que a religião pode ter sobre a decisão das pessoas quanto a tratamentos e terapias é evidenciada em alguns casos, como o da transfusão sanguínea. Carvalho et al. ${ }^{30}$ destacam a influência da religiấo na conduta da populaçấo frente à imunização. Embora não exista uma imposição jurídica do Estado, é possível observar que os valores culturais permeiam essa prática. Dessa forma, é importante conhecer a cultura, os valores, as crenças e o modo de vida da comunidade. Daí o motivo de incluir essa questão no presente trabalho.

Quanto à vacinação, não foi possível evidenciar nesta pesquisa a religião como motivo para não adesão à $2^{a}$ dose da vacina H1N1.O grau de escolaridade dos entrevistados pode ser visto no Gráfico 7 .

Gráfico 7: Grau de escolaridade dos responsáveis por levar as crianças para serem vacinadas.

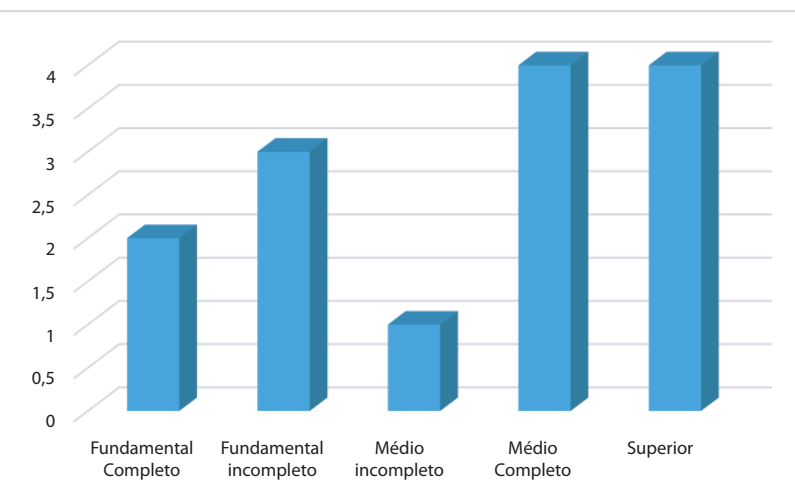

Percebe-se que $46 \%$ da população pesquisada não concluiu o segundo grau. As taxas de analfabetismo estâo reduzindo com o tempo, tanto na área urbana como rural. No Brasil, a taxa de analfabetismo para as mulheres com dez ou mais anos de idade é de 8,7\%. Para as mulheres com 15 anos ou mais a taxa de analfabetismo é de 9,3\% segundo os dados da Pesquisa Nacional de Domicílios do IBGE ${ }^{26}$.

A escolaridade depende muito das políticas públicas de cada país ou região. Além disso, Silva et al. ${ }^{31}$ afirmam que fatores como idade, sexo, renda, raça/cor, escolaridade e tipo de cobertura influenciam no uso e na elaboração de distintos sistemas de saúde pelo mundo.

Analisando a evolução do perfil de utilizaçâo de serviços de saúde, entre 2003 e 2008, verifica-se que houve maior procura por serviços de saúde nos extremos de escolaridade ( 0 a 3 anos e 11 ou mais anos de estudo, $16 \%$ e $15 \%$, respectivamente, contra $14 \%$ nas faixas de escolaridade intermediárias).

Os gradientes de utilização de serviços de saúde, segundo escolaridade e renda, observados em 2003 se mantiveram em 2011, mostrando que as condiçóes socioeconômicas estão associadas ao acesso e à utilização dos serviços de saúde.

Segundo pesquisas de Carvalho $^{30}$ e Peixoto e Torquato $^{32}$, a baixa escolaridade influenciou na baixa adesão ao PNI. Além disso, como ressaltam Silva e Borges $^{33}$, é importante relatar a escolaridade da mãe em 
estudos que envolvem saúde da criança, pois o grau de escolaridade pode estar relacionado com o conhecimento dos cuidados que ela deve ter com seus filhos.

A ocupaçáo dos responsáveis das crianças pode ser vista no Gráfico 8.

Gráfico 8: Ocupação dos responsáveis por levar as crianças para serem vacinadas.

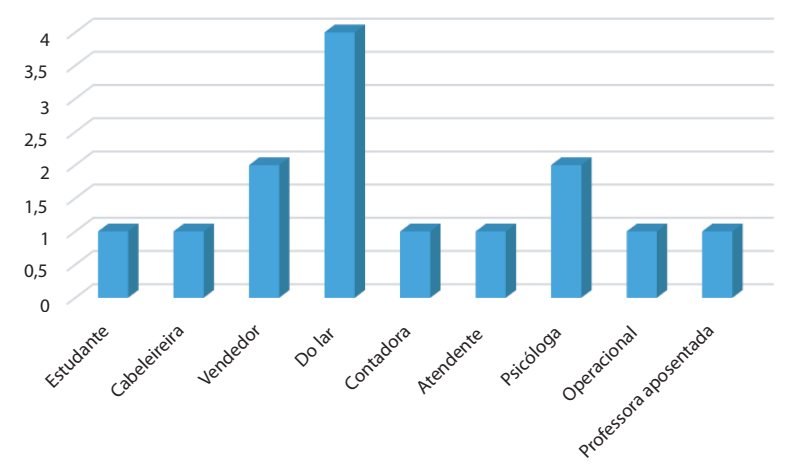

Como cita o Painel de Indicadores do SUS ${ }^{34}$, os determinantes sociais da saúde (DSS) incluem as condiçóes socioeconômicas, culturais e ambientais de uma sociedade e têm relaçáo direta com habitaçáo, saneamento, educação, serviços de saúde etc.

Dados recentes mostram que em 2009 houve um aumento na inserção no trabalho formal para ambos os sexos $-53,2 \%$ para o homem e $48,8 \%$ para a mulher. Esse fato reforça o papel da mulher enquanto provedora da família, corroborando o Censo Demográfico de $2010^{34}$, o qual indica que 22 milhões de mulheres são responsáveis pela unidade doméstica.

No entanto, a diferença entre o rendimento dos homens e das mulheres foi expressiva em todas as grandes regióes.

O rendimento médio mensal das mulheres representou $70,6 \%$ do auferido pelos homens no país. Nas grandes regiōes, esse percentual variou de $70,3 \%$ na região Sul a $75,5 \%$ na Norte. Mesmo quando a mulher apresenta 12 anos ou mais de estudo, o seu rendimento representa $58 \%$ do salário do homem com o mesmo nível de escolaridade ${ }^{34}$.

É importante enfatizar que, de acordo com Ruaro, Johnson e Ramos ${ }^{35}$, em nosso país, 27,5\% dos lares são sustentados pelo trabalho da mulher - mesmo com a discrepância entre o seu salário e o do homem -, mas apesar desse fato, há empregadores que ainda consideram o salário feminino como mero complemento do salário masculino ${ }^{36}$.

Como se verifica no trabalho de Silva et al..$^{37}$, a baixa renda familiar se destaca como fator de risco para a não vacinação. Por isso é necessário analisar a ocupação da mulher no mercado de trabalho, pois já são comprovados níveis mais baixos de vacinação entre os mais pobres $^{38}$. As baixas condiçóes de vida fazem as mães não levarem seus filhos adequadamente à vacinação, pois enfrentam numerosas dificuldades no seu cotidiano.

Contrariamente, não se observou no presente estudo diferença na cobertura vacinal segundo a renda familiar, demonstrando a necessidade de se desenvolverem esforços para incrementar as coberturas vacinais em toda a população.

Ao final da entrevista, questionou-se aos participantes: "Qual o motivo pelo qual seu(ua) filho(a) não recebeu a $2^{a}$ dose da vacina H1N1 no Centro de saúde Escola Jaraguá?”. As respostas que emergiram durante a pesquisa foram inseridas na Tabela 2 .

Tabela 1: Motivos da não vacinação dos filhos dos entrevistados, $1^{\text {a }}$ dose.

\begin{tabular}{|ccc|}
\hline Respostas evidenciadas na pesquisa & N & $\%$ \\
\hline Ausência de informaçáo & 1 & 7,14 \\
\hline Foi imunizado em outro local & 11 & 78,57 \\
\hline Falta de vacina & 2 & 14,29 \\
\hline
\end{tabular}

A ausência de informação quanto à necessidade do retorno à unidade de saúde para receber a $2^{\mathrm{a}}$ dose da vacina foi uma das respostas que surgiram durante a pesquisa.

Tabela 2: Motivos da não vacinação dos filhos dos entrevistados, $2^{\text {a }}$ dose.

\begin{tabular}{|ccc|}
\hline Respostas evidenciadas na pesquisa & N & $\%$ \\
\hline Ausência de informaçáo & 9 & 64,29 \\
\hline Foi imunizado em outro local & 3 & 21,43 \\
\hline Falta de vacina & 2 & 14,29 \\
\hline
\end{tabular}

Nesse sentido, os estudos de Silva e Botti ${ }^{39}$ evidenciam que a informação negligenciada, não dada propositadamente (ou de forma fragmentada), usando termos técnicos de difícil compreensão, dificultam o tratamento dos pacientes.

De acordo com a pesquisa de Pastore, Prates e Gutierrez ${ }^{40}$, os resultados referentes ao conhecimento prévio sobre a influenza $\mathrm{H} 1 \mathrm{~N} 1$ demonstram mais de $80 \%$ das respostas certas. Quanto à vacina e sua importância, a maior parcela da população reconhecia a importância da imunização, compreendia para quais pessoas a vacina era indicada e conhecia os possíveis efeitos colaterais.

No entanto, na presente pesquisa esse fato não se evidenciou dessa forma, pois a maioria dos entrevistados não retornou à unidade para que a criança recebesse a $2^{\mathrm{a}}$ dose da vacina, alegando falta de informação a respeito.

Questiona-se entáo a qualidade com que a informação é divulgada para a população, seja pela mídia ou pelos profissionais de saúde. Evidencia-se a necessidade de mais investimentos em iniciativas que possibilitem a aquisição dos conhecimentos por parte do público-alvo, pois as primeiras doses, principalmente durante as campanhas, são 
muito bem divulgadas, existindo, porém, menos divulgaçấo quando se trata da segunda dose.

Como mostram Buss e Pellegrini Filho ${ }^{41}$, é muito difícil mudar comportamentos de risco sem mudar as normas culturais que os influenciam. Atuando exclusivamente sobre os indivíduos, é possível que alguns deles mudem de comportamento, mas logo eles serão substituídos por outros. Para atuar nesse nível de maneira eficaz, são necessárias políticas de abrangência populacional que mudem o comportamento da população, por meio de programas educativos, comunicação social e acesso facilitado a alimentos saudáveis. De acordo com o $\mathrm{MS}^{42}$, a divulgaçâo das normas de vacinação para os profissionais de saúde ressalta a importância do cumprimento do calendário para ampliar a cobertura vacinal.

Outro motivo de as crianças não terem recebido a $2^{\text {a }}$ dose da vacina vai ao encontro dos estudos de Colombe $^{43}$, que demonstra um descompasso entre a informação do cartão-espelho da criança (fichas de registro) na unidade de saúde e o que estava anotado no cartão de vacina da criança mostrando a situação real. Essa discordância se deu porque os pais/familiares optaram por levar os filhos em outras instituiçóes de saúde para dar continuidade ao esquema de vacina. Ou seja, o cartáo-espelho da criança não representa sua situação real de imunização. Portanto, observa-se a importância da busca ativa dos faltosos para terem dados fidedignos da cobertura vacinal e, além disso, incentivar a promoção de açóes educativas ampliadas à comunidade.

A falta de vacina foi outro motivo citado para a não adesão, embora O MS, por meio do PNI, alega distribuir vacinas aos estados e municípios. Peixoto e Torquato ${ }^{32}$ evidenciaram que $20 \%$ dos responsáveis deixaram de vacinar os seus filhos por falta de vacina na unidade de saúde. Essa porcentagem não traduziu a maioria da pesquisa, mas foi suficiente para atrasar o cartão de vacina de seis crianças. Conforme Souza e Teixeira ${ }^{44}$, estudos adicionais poderiam contribuir para uma melhor compreensão da aceitação de vacinaçáo entre os diferentes subgrupos dos grupos-alvo no Brasil e para um melhor planejamento de futuras campanhas de imunização.

Analisando os motivos citados nas entrevistas, é importante enfatizar que nesta pesquisa a adesão à $2^{\text {a }}$ dose da vacina foi de $74 \%$, portanto menor que a meta do MS para 2010 , que era de $80 \%$ para a vacinação de crianças menores de 2 anos (essa expectativa foi superada no Brasil, atingindo $96,5 \%)^{16}$.

Dados do ministério revelam que, no ano de 2009, crianças entre 6 meses e 2 anos tiveram a maior taxa de incidência de complicaçóes da doença - 154 casos para cada 100 mil habitantes ${ }^{16}$. No entanto, nâo foram evidenciadas na análise das entrevistas do presente trabalho as complicaçóes relacionadas à vacina. Dessa forma, não se configurou como motivo para a não adesão à $2^{\text {a }}$ dose.

\section{Conclusão}

O propósito desta pesquisa foi analisar os fatores que levaram as mães/acompanhantes de crianças de 0 a 2 anos a não manterem o cartáo de vacina das crianças em dia na sala de vacinação, mostrar as influências dos aspectos sociais e epidemiológicos, evidenciar as questôes culturais e caracterizar o perfil dos pais em relação à vacina contra $\mathrm{H} 1 \mathrm{~N} 1$.

Os dados socioepidemiológicos e culturais da pesquisa não influenciaram a não adesão à $2^{\mathrm{a}}$ dose da vacina. Além disso, podemos concluir que a mulher foi a personagem principal no trato de questóes de saúde.

Após a análise das entrevistas, foi possível observar que existem fatores como a ausência de informaçáo quanto à necessidade do retorno à unidade de saúde para completar o esquema de vacinação, o descompasso entre a informação da ficha de registro na unidade de saúde e o que estava anotado no cartão da criança, além da falta de vacina na unidade, o que interfere em manter o cartão das crianças atualizado.

Portanto, ressalta-se a importância da busca ativa dos faltosos para se obter dados fidedignos quanto à cobertura vacinal.

Pode-se dizer que os objetivos foram alcançados quanto ao fato de analisar as causas da não adesão de $36,6 \%$ dos entrevistados à $2^{\text {a }}$ dose da vacina. Devido a dificuldades, como a localizaçâo dos sujeitos da pesquisa, a análise de alguns dados ficou limitada, embora não tenham prejudicado o alcance das metas do estudo.

Este trabalho possibilitou o acesso a informaçóes a respeito da adesão à $2^{a}$ dose da vacina contra $\mathrm{H} 1 \mathrm{~N} 1$, caracterizando a população de uma unidade de saúde. Além disso, permitiu uma reflexâo sobre a importância da mobilização popular quanto às campanhas de imunização, contribuindo para alcançar as metas do PNI.

Como destacam Silva et al. ${ }^{36}$, apesar da melhoria nas coberturas vacinais observadas no Brasil, uma parcela das crianças continua sem ser vacinada adequadamente, mesmo em locais com ampla disponibilidade de serviços de saúde.

A temática deste estudo poderá ser mais explorada em pesquisas futuras, pois há muitas questôes complexas relacionadas à não adesão a vacina contra $\mathrm{H} 1 \mathrm{~N} 1$.

\section{Referências}

1. Brasil. Ministério da Saúde. Programa Nacional de Imunizaçóes. Campanha Nacional de Vacinação contra a Influenza 2011. Brasília, DF: Ministério da Saúde; 2011.

2. Brasil. Ministério da Saúde. Programa Nacional de Imunização. Campanha Nacional de Vacinação contra a Influenza 2012. Brasília, DF: Ministério da Saúde; 2012. 
3. Machado AA. Infecção pelo vírus Influenza A (H1N1) de origem suína: como reconhecer, diagnosticar e prevenir. J Bras Pneumol. 2009;35(5):464-9.

4. Pinhati HMS. Influenza A (H1N1): há motivos para preocupação? Bras Med. 2009;46(1):6-9.

5. Andrade CR, Ibiapina CC, Champs NS, Toledo Junior ACC, Picinin IFM. Gripe aviária: a ameaça do século XXI. J Bras Pneumol. 2009;35(5):470-9.

6. Rezende MS. Gripe aviária, aves migratórias e o controle sanitário na criação de aves comerciais e de subsistência no município de Uberlândia - Minas Gerais [dissertação]. Uberlândia: Universidade Federal de Uberlândia; 2009.

7. Greco DB, Tupinambás U, Fonseca M. Influenza A (H1N1): histórico, estado atual no Brasil e no mundo, perspectivas. Rev Méd Minas Gerais. 2009;19(2):132-9.

8. Verrastro CGY, Abreu Junior L, Hitomi DZ, Antonio EP, Neves AR, D'Ipollito G. Manifestaçóes da infecção pelo novo vírus influenza $A(\mathrm{H} 1 \mathrm{~N} 1)$ na tomografia computadorizada de tórax. Radiol Bras. 2009;42(6):343-8.

9. Brasil. Agência Nacional de Vigilância Sanitária. Protocolo de vigilância epidemiológica de eventos adversos pós-vacinação. Brasília, DF: Ministério da Saúde; 2010.

10. Gatti MAN, Oliveira LR. Crianças faltosas à vacinação, condiçóes de vida da família e concepção sobre vacina: um inquérito domiciliar. Rev Salusvita. 2005;24(3):427-45.

11. Gil AC. Como elaborar projetos de pesquisa. São Paulo: Atlas; 2002.

12. Santos ZMSA, Albuquerque VLM, Sampaio FHS. Vacinaçáo: o que o usuário sabe? Rev Bras Promoç Saúde. 2005;18(1):23-30.

13. Brasil. Ministério da Saúde. Departamento de Informática do SUS. Sistema de Informação do Programa Nacional de Imunizaçóes [Internet]. [atualizado em 2017; citado em 2015 jan 1]. Disponível em: http://www2.datasus.gov. br/DATASUS/index.php

14. Temporão JGO. Programa Nacional de Imunizaçôes (PNI): origens e desenvolvimento. História, Ciências, Saúde. 2003;2(10):601-17.

15. Homma A, Martins RM, Leal FML, Freire MS, Couto AR. Atualização em vacinas, imunizaçóes e inovação tecnológica. Ciênc Saúde Coletiva. 2011;16(2):445-58.

16. Brasil. Ministério da Saúde. Estratégia nacional de vacinação contra o vírus influenza pandêmico (H1N1) 2009. Brasília, DF: Secretaria de Vigilância em Saúde; 2010.

17. Duarte PAD, Venazzi A. Pacientes com infecção por vírus $A$ (H1N1) admitidos em unidades de terapia intensiva do Estado do Paraná, Brasil. Rev Bras Ter Intensiva. 2009;21(3):231-6.

18. Vranjac A. Características dos casos notificados de Influenza A/H1N1. Rev Saúde Públ. 2009;43(5):900-4.

19. Cintra OAL, Rey LC. Segurança, imunogenicidade e eficácia da vacina contra o vírus influenza em crianças. J Pediatr. 2006;82(3):83-90.
20. Donalisio MR. Política brasileira de vacinação contra a influenza e seu impacto sobre a saúde do idoso. Cad Saúde Públ. 2007;23(3):494-5.

21. Castilho SG, Bercini LO. Acompanhamento de saúde da criança: concepçóes das famílias do município de Cambira, Paraná. Ciênc Cuid Saúde. 2005;4(2):129-38.

22. Gutierrez DMD, Minayo MCS. Produção de conhecimento sobre cuidados da saúde no âmbito da família. Ciênc Saúde Coletiva. 2010;15(1):1497-508.

23. Rocha R, Sampaio MJ, Pereira CL, Liberal I. Factores associados ao não cumprimento do Programa Nacional de Vacinação e das vacinas pneumocócica conjugada heptavalente e contra o rotavírus. Acta Pediátr Portug. 2010;41(5):195-200.

24. Moscon N, Kruger TR. O serviço social na atenção básica e o acesso aos serviços de saúde. Rev Saúde Pública Santa Catarina. 2010;3(2):88-98.

25. Figueiredo GLA, Pina JC, Tonete VLP, Lima RAG, Mello DF. Experiências de famílias na imunização de crianças brasileiras menores de dois anos. Rev Latin Amer Enferm. 2011;19(3):8.

26. Brasil. Instituto Brasileiro de Geografia e Estatística. Orçamento e Gestão. Síntese de indicadores sociais: uma análise das condiçôes de vida da população brasileira. Rio de Janeiro: Ministério do Planejamento; 2010.

27. Brasil. Instituto Brasileiro de Geografia e Estatística. Ministério do Planejamento, Orçamento e Gestáo. Censo demográfico 2010: características da população e dos domicílios. Resultados do Universo. Rio de Janeiro; 2010.

28. Adorno RCF, Alvarenga AT, Vasconcellos MP. Quesito cor no sistema de informação em saúde. Est Av. 2004;18(50):119-23.

29. Raymundi SD. Aspectos da não adesão de idosos à campanha de vacinação da gripe no bairro córrego grande [monografia]. Florianópolis: Universidade Federal de Santa Catarina; 2004.

30. Carvalho KM, Araújo TME, Silva GRF, Luz MHBA. A cultura de imunização no Brasil: reflexões a partir da Teoria do Cuidado Transcultural. Rev Enferm UFPI. 2012;1(3):226-9.

31. Silva ZP, Ribeiro MCSA, Barata RB, Almeida MF. Perfil sociodemográfico e padrão de utilização dos serviços de saúde do Sistema Único de Saúde (SUS), 2003-2008. Ciênc Saúde Coletiva. 2011;16(9):3807-16.

32. Peixoto AR, Torquato RS. Razóes que levam os pais ao incumprimento do esquema vacinal recomendado para os seus filhos [monografia]. Barcarena: Escola Superior de Saúde Atlântica; 2009.

33. Silva V, Borges GC. Levantamento da cobertura vacinal de crianças de 0 a 1 ano cadastradas em um esf da cidade de Dourados/MS. Interbio. 2011;5(1):37-43.

34. Brasil. Ministério da Saúde. Painel de Indicadores do SUS no 7. Brasília, DF: Secretaria de Gestão Estratégica e Participativa; 2010.

35. Ruaro GCG, Johnson GA, Ramos F. Participação política feminina em cargos públicos decisórios municipais: um estudo de caso. Cad Espaço Fem. 2009;22(2):241-65. 
36. Corral T. Agenda de desenvolvimento humano e sustentável par o Brasil do século XXI. Brasília, DF: PNUD; 2000.

37. Silva AAM, Gomes AU, Tonial SR, Silva RA. Cobertura vacinal e fatores de risco associados à não-vacinação em localidade urbana do Nordeste brasileiro, 1994. Rev Saúde Públ. 1999;33(2):147-56.

38. Tertuliano GC, Stein AT. Atraso vacinal e seus determinantes: um estudo em localidade atendida pela estratégia Saúde da Família. Ciênc Saúde Coletiva. 2011;16(2):523-30.

39. Silva ET, Botti NCL. Depressão puerperal. Rev Eletr Enferm. 2005;7(2):231-8.

40. Pastore APW, Prates CS, Gutierrez LLP. Conhecimento sobre a influenza $\mathrm{A}(\mathrm{H} 1 \mathrm{~N} 1)$ pdm09 entre indivíduos vacinados no Centro Universitário Metodista IPA, Porto Alegre, Rio Grande do Sul. Scientia Medica. 2012;22(4):197-202.

41. Buss PM, Pellegrini Filho A. A saúde e seus determinantes sociais. Rev Saúde Coletiva. 2007;17(1)77-93.

42. Brasil. Ministério da Saúde. Inquérito de cobertura vacinal nas áreas urbanas das capitais. Brasília, DF: Centro de Estudos Augusto Leopoldo Ayrosa Galvão; 2007.

43. Colombe RM. Oportunidades perdidas para a vacinação de menores de 1 ano. In: Anais da 9a Mostra Acadêmica Unimep; 2011, Piracicaba: Unimep; 2011. p. 328-33.

44. Souza EP, Teixeira MS. Cobertura vacinal para influenza A/ $\mathrm{H} 1 \mathrm{~N} 1$, reaçóes adversas e motivos para a não aceitaçáo da vacina entre os estudantes de medicina no Brasil. Rev Inst Med Trop S Paulo. 2012;54(2):77-82.

\section{Como citar este artigo:}

Dias LP, Dias MP. Avaliação dos fatores relacionados à não adesão à segunda dose da vacina H1N1 em um centro de saúde-escola. Rev. Aten. Saúde. 2017;15(51):34-45. 


\section{ANEXO}

\section{Formulário}

\section{Grau de parentesco}
( ) Pai
( ) Mãe
( ) Avós
( ) Irmãos
( ) Outros familiares
Especificar:

\section{Dados pessoais}

Faixa etária:

( ) 18 a 25 anos

( ) 26 a 32 anos

( ) 33 a 39 anos

( ) Acima de 45 anos

Procedência:

( ) Uberlândia

( ) Outros municípios de Minas Gerais

( ) Outros estados

Tempo gasto da sua residência/unidade de saúde:
( ) Até 10 minutos
( ) Até 20 minutos
( ) Até 30 minutos
( ) Até 1 hora
( ) Acima de 1 hora
Especificar:

\section{Meio de locomoção usado}
( ) Bicicleta
( ) Carro
( ) Ônibus
( ) A pé
( ) Outros
Especificar:

\section{Etnia}
( ) Branco
( ) Pardo
( ) Negro
( ) Amarelo

\section{Religiáo:}

\section{Grau de escolaridade}

( ) Não alfabetizado

( ) Fundamental completo

( ) Fundamental incompleto

( ) Médio completo

( ) Médio incompleto

( ) Superior

\section{Profissão/ocupação:}

Qual o motivo pelo qual seu(ua) filho(a) não recebeu a $2^{a}$ dose da vacina $\mathrm{H} 1 \mathrm{~N} 1$ ? 